\section{OPEN ACCESS}

Edited and reviewed by:

Martijn van Griensven,

Maastricht University, Netherlands

${ }^{*}$ Correspondence: Owen G. Davies

O.G.Davies@lboro.ac.uk

Specialty section

This article was submitted to

Tissue Engineering and Regenerative

Medicine,

a section of the journal

Frontiers in Bioengineering and

Biotechnology

Received: 30 August 2019 Accepted: 20 November 2019 Published: 06 December 2019

Citation:

Davies OG, Cox SC, Azoidis I,

McGuinness AJA, Cooke M, Heaney LM, Davis ET, Jones SW and Grover LM (2019) Corrigendum: Osteoblast-Derived Vesicle Protein

Content Is Temporally Regulated During Osteogenesis: Implications for Regenerative Therapies.

Front. Bioeng. Biotechnol. 7:392. doi: 10.3389/fbioe.2019.00392

\title{
Corrigendum: Osteoblast-Derived Vesicle Protein Content Is Temporally Regulated During Osteogenesis: Implications for Regenerative Therapies
}

\begin{abstract}
Owen G. Davies ${ }^{1 *}$, Sophie C. Cox ${ }^{2}$, loannis Azoidis², Adam J. A. McGuinness ${ }^{3}$, Megan Cooke ${ }^{2,3}$, Liam M. Heaney ${ }^{1}$, Edward T. Davis ${ }^{4}$, Simon W. Jones ${ }^{5}$ and Liam M. Grover ${ }^{2}$

${ }^{1}$ School of Sport, Exercise and Health Sciences, Loughborough University, Loughborough, United Kingdom, ${ }^{2}$ School of Chemical Engineering, University of Birmingham, Birmingham, United Kingdom, ${ }^{3}$ Physical Sciences for Health Doctoral Training Centre, University of Birmingham, Birmingham, United Kingdom, ${ }^{4}$ Royal Orthopaedic Hospital, Birmingham, United Kingdom, ${ }^{5}$ Institute of Inflammation and Ageing, University of Birmingham, Birmingham, United Kingdom
\end{abstract}

Keywords: vesicle, mineralization, annexin, collagen, osteoblast, nano

\section{A Corrigendum on}

Osteoblast-Derived Vesicle Protein Content Is Temporally Regulated During Osteogenesis: Implications for Regenerative Therapies

by Davies, O. G., Cox, S. C., Azoidis, I., McGuinness, A. J. A., Cooke, M., Heaney, L. M., et al. (2019). Front. Bioeng. Biotechnol. 7:92. doi: 10.3389/fbioe.2019.00092

"Edward T. Davis" and "Simon W. Jones" were not included as authors in the published article. The author list has been updated and the corrected Author Contributions statement appears below.

"OD conception of study. OD, SC, SJ, ED, and LG experimental design and manuscript preparation. OD, IA, AM, SJ, ED, and MC experimental work and data analysis. LH computational data analysis."

Additionally, in the original article, there was a mistake in Table $\mathbf{1}$ as published. Incorrect primers were included. The corrected Table 1 appears below.

The authors apologize for these errors and state that it does not change the scientific conclusions of the article in any way. The original article has been updated.

Copyright $\odot 2019$ Davies, Cox, Azoidis, McGuinness, Cooke, Heaney, Davis, Jones and Grover. This is an open-access article distributed under the terms of the Creative Commons Attribution License (CC BY). The use, distribution or reproduction in other forums is permitted, provided the original author(s) and the copyright owner(s) are credited and that the original publication in this journal is cited, in accordance with accepted academic practice. No use, distribution or reproduction is permitted which does not comply with these terms. 
TABLE 1 | Primer sequences and accompanying gene accession numbers.

\begin{tabular}{|c|c|c|c|}
\hline Gene & Forward & Reverse & Accession No. \\
\hline ALP & CTTGGGCAGGCAGAGAGTA & AGTGGGAGGGTCAGGAGAT & NM_000478 \\
\hline BGLAP & GGCACCCTTCTाССTCTTC & TTCTGGAGTIATITGGGAGCA & NM_199173 \\
\hline BSP & GAGGTGATAGTGTGGTIATGGA & TGATGTCCTCGTCTGTAGCA & NM_00104005 \\
\hline COL1A1 & AGACAGTGATTGAATACAAAACCA & GGAGTITACAGGAAGCAGACA & NM_000088 \\
\hline
\end{tabular}

